\title{
Comparison of the effects of basil (Ocimum basilicum) essential oil, avilamycin and protexin on broiler performance, blood biochemistry and carcass characteristics
}

\author{
S. R. Riyazi ${ }^{1}$, Y. Ebrahimnezhad ${ }^{1}$, S. A. Hosseini ${ }^{2}$, A. Meimandipour ${ }^{3}$, and A. Ghorbani ${ }^{1}$ \\ ${ }^{1}$ Department of Animal Science, Islamic Azad University, Shabestar Branch, Shabestar, East Azerbaijan, Iran \\ ${ }^{2}$ Animal Science Research Institute of Iran, Karaj, Iran \\ ${ }^{3}$ Animal Biotechnology Department, National Institute of Genetic Engineering \\ and Biotechnology, Tehran, Iran \\ Correspondence to: Y. Ebrahimnezhad (ebrahimnezhad@gmail.com)
}

Received: 28 July 2015 - Revised: 17 October 2015 - Accepted: 3 November 2015 - Published: 25 November 2015

\begin{abstract}
The effects of a probiotic (protexin), a medicinal plant (basil essential oil) and an antibiotic growth promoter (avilamycin) as broiler feed additives on performance, carcass characteristics and some blood parameters of broilers were studied. A total of 600 Arian broilers were divided into six treatments, with four replicates of 25 birds. Treatments were a plant essential oil in three levels (200, 400 and 600 ppm), the probiotic (150 ppm), the antibiotic $(150 \mathrm{ppm})$ and a control group with no additives. Birds in different treatments received the same diets during the experimental period. Growth performance, blood biochemical parameters and carcass traits were measured. There were no effects of dietary treatment on body weight gain, feed intake and feed conversion ratio of the broilers. Internal organ weights and carcass characteristics were not influenced by treatments; however, 200 ppm basil essential oil supplementation decreased abdominal fat $(P<0.05)$. Biochemical parameters including serum low-density lipoprotein (LDL), high-density lipoprotein (HDL) and total cholesterol were not statistically influenced. However, addition of $400 \mathrm{ppm}$ basil essential oil into diet increased serum triglyceride as compared to the control $(P<0.05)$. Results of this experiment demonstrated that the herbal natural feed additives such as basil may be used as alternatives to an antibiotic growth promoter without any adverse effects on broiler production.
\end{abstract}

\section{Introduction}

With the development and wide use of synthetic and semisynthetic antibiotics, pros and cons have been experienced throughout the last 50 years which have directed research back to natural antimicrobial products as indispensable resources (Lavinia et al., 2009). Consequently, the use of antibiotics for broilers has been limited in the European Union to only four antibiotics that are not associated with human treatment. They are avilamycin and flavophospholipol as growth promoter additives and salinomycin sodium and monensin sodium as coccidiostats (Hernandez et al., 2004).
Avilamycin is an oligosaccharide antibiotic of the orthosomycin group. Avilamycin is rapidly and extensively metabolized by the gastrointestinal tract and can be used in broilers without the need for a preslaughter withdrawal period (Wellenreiter et al., 2000). There are several proposed mechanisms for the performance-enhancing effects of avilamycin. Some of the mechanisms revolve around a glucosesparing effect, a reduction in lactate production, and increased volatile fatty acid production and absorption in the lower gut of the broiler (Wellenreiter et al., 2000). Probiotics and essential oils are the most promising alternatives to antibiotics. Probiotics are live microbacteria, and their fermentation products beneficially reduce the undesirable mi- 
croflora population in the gastrointestinal tract of chicks (Chiang and Hsieh, 1995; Khan et al., 2012; Dhama et al., 2015). It has been reported that probiotics benefit the host animal by stimulating synthesis of B-group vitamins, improving immunity stimulation, preventing harmful microorganisms, providing digestive enzymes and increasing the production of volatile fatty acids (Fuller, 1989). Another antibiotic alternative is essential oils, which are being used as feed supplements to improve growth performance and the microbial habitat of domestic animals and to manipulate gut functions. Volatile oils found in plants can inhibit the activity of the liver enzyme (HMG-CoA reductase) that regulates the amount of synthesized cholesterol and thus reduce its blood levels (Bolukbasi et al., 2008). According to Case et al. (1995), a $5 \%$ reduction of HMG-CoA reductase lowered serum cholesterol by $2 \%$ in poultry. Qureshi et al. (1983) reported a correlation between $\mathrm{HMG}-\mathrm{CoA}$ reductase activity and either total or low-density lipoprotein (LDL) cholesterol in chickens, but not with high-density lipoprotein (HDL) cholesterol. It has been reported that, when cockerels are fed dietary limonene at levels of 25-100 ppm for 26 days, hepatic HMG-CoA reductase activity and serum cholesterol show a dose-dependent decrease, whereas hepatic fatty acid synthetase activity was unaffected (Qureshi et al., 1983).

Essential oils are composed of a complex mixture of active substances extracted from plants through a steam distillation process or generated via chemical synthesis (Traesel et al., 2011).

Basil (Ocimum basilicum), also known as sweet and garden basil, a member of the Lamiaceae family, is commonly cultivated throughout the Mediterranean region (Abbas, 2010). The leaves and flowering tops of sweet basil are used as a carminative, galactogogue, stomachic and antispasmodic in folk medicine (Sajjadi, 2006). However, recently the potential uses of $O$. basilicum essential oils, particularly as antimicrobial and antioxidant agents, have also been investigated. The chemical composition of basil oil has been the subject of a considerable number of studies. There is extensive diversity in the constituents of the basil oils, and several chemotypes have been established from various phytochemical investigations (Sajjadi, 2006). However, methyl chavicol, linalool, methyl cinnamate, methyl eugenol, eugenol and geraniol are reported as major components of the oils of different chemotypes of $O$. basilicum (Sajjadi, 2006). Several studies have demonstrated that the supplementation of avilamycin or probiotics in broiler diets increased growth performance and reduced diseases and management problems (Wellenreiter et al., 2000; Vahdatpour et al., 2011; Yakhkeshi et al., 2011). Also, many studies have also been conducted on the effects of dietary essential oils or combinations on the performance of poultry, but with varying and conflicting results. While some reports (Alcicek et al., 2003; Brenes and Roura, 2010; Bozkurt et al., 2012) have demonstrated that essential oils improved animal performance, some researchers (Lee et al., 2003a, b; Botsoglou et al., 2003, 2004) have reported that these additives were not effective in this regard. Besides that, essential oils enhance production of digestive secretions, stimulate blood circulation, exert antioxidant properties, reduce levels of pathogenic bacteria and may enhance immune status (Hosseini et al., 2013a). The aim of the present study was to investigate and compare the effects of an essential oil (basil), an antibiotic (avilamycin) and a probiotic (protexin) on performance, blood biochemistry and carcass characteristics in broilers.

\section{Materials and methods}

Six hundred 1-day-old broiler chicks (Arian strain) were purchased from a local hatchery. On arrival birds were weighed and randomly assigned to one of six treatments with four replicates of 25 birds based on a completely randomized design. The dietary treatments consisted of the basal diet as control and five test diets containing $150 \mathrm{ppm}$ avilamycin as an antibiotic; $150 \mathrm{ppm}$ protexin as a probiotic; and 200, 400 and 600 ppm basil essential oil. Protexin is a mixture of advantageous bacteria containing Lactobacillus acidophilus, Lactobacillus plantarum, Lactobacillus rhamnosus, Lactobacillus bulgaricus, Streptococcus thermophilus, Aspergillus oryzae, Bifidobacterium bifidum, Enterococcus faecium, and Candida pintolepesii, with a minimum of $6 \times 10^{7} \mathrm{cfu} \mathrm{g}^{-1}$ of product. Table 1 lists the basal diet formulated to meet or exceed the nutrient requirements of broilers provided by the Arian broiler manual. Chicks were raised on floor pens $(120 \times 120 \times 80 \mathrm{~cm})$ for 6 weeks and had free access to food and water through the entire experimental period (142 days). The uniform light was provided $24 \mathrm{~h}$ per day. The ambient temperature was gradually decreased from 33 to $25^{\circ} \mathrm{C}$ on day 21 and was then kept constant. The basil essential oil was obtained from Ayat Esans Company (Tehran, Iran). The oil obtained was immediately analyzed using gas chromatography-mass spectrometry (GC-MS) to identify the chemical constituents present in the essential oil. Table 2 shows the composition of basil essential oil and the amount of each component.

\subsection{Animal performance}

Measurements of broiler performance including body weight gain, daily feed consumption, feed conversion ratio and mortality were determined. The body weight of birds per replicate was recorded on an individual basis at weekly intervals and cumulatively. The feed consumption per replicate was recorded on a weekly basis and cumulatively. The feed conversion ratio per replicate was calculated at weekly intervals by taking into consideration the weekly body weight gain and the feed consumption of the respective replicate. Feed intake and the feed conversion ratio were adjusted for mortality. 
Table 1. The nutritional composition of dietary treatments.

\begin{tabular}{|c|c|c|c|}
\hline $\begin{array}{l}\text { Ingredients } \\
(\%)\end{array}$ & $\begin{array}{r}\text { Starter } \\
(1-14 \text { days })\end{array}$ & $\begin{array}{r}\text { Grower } \\
\text { (14-28 days) }\end{array}$ & $\begin{array}{r}\text { Finisher } \\
\text { (28-42 days) }\end{array}$ \\
\hline Corn & 48.60 & 45.70 & 45.55 \\
\hline Soybean meal (44\% CP) & 36.50 & 32.00 & 27.90 \\
\hline Wheat & 6.78 & 15.00 & 20.00 \\
\hline Fish meal & 2.10 & 1.40 & 0.50 \\
\hline Soybean oil & 1.60 & 2.10 & 2.00 \\
\hline Dicalcium phosphate & 1.90 & 1.68 & 1.80 \\
\hline Oyster shell & 1.25 & 1.05 & 1.10 \\
\hline Salt & 0.25 & 0.25 & 0.25 \\
\hline Vitamin premix $^{1}$ & 0.25 & 0.25 & 0.25 \\
\hline Mineral premix ${ }^{2}$ & 0.25 & 0.25 & 0.25 \\
\hline Sodium bicarbonate & 0.20 & 0.15 & 0.15 \\
\hline DL-methionine & 0.27 & 0.17 & 0.18 \\
\hline L-lysine & 0.05 & - & 0.07 \\
\hline \multicolumn{4}{|l|}{ Calculated composition } \\
\hline $\operatorname{ME}\left(\mathrm{kcal} \mathrm{kg}^{-1}\right)$ & 2851 & 2937 & 2965 \\
\hline Crude protein $(\%)$ & 22.23 & 20.39 & 18.5 \\
\hline Calcium (\%) & 1.06 & 0.90 & 0.90 \\
\hline Available phosphorus (\%) & 0.50 & 0.45 & 0.45 \\
\hline Methionine & 0.63 & 0.49 & 0.47 \\
\hline Met + Cys (\%) & 0.99 & 0.83 & 0.78 \\
\hline Lysine (\%) & 1.28 & 1.10 & 1.00 \\
\hline Threonine (\%) & 0.85 & 0.77 & 0.69 \\
\hline Tryptophan (\%) & 0.32 & 0.29 & 0.26 \\
\hline
\end{tabular}

Table 2. Composition of basil essential oil.

\begin{tabular}{llr|llr}
\hline Peak & Constituents & $\begin{array}{r}\text { Total identified } \\
\text { peaks } \%\end{array}$ & Peak & Constituents & $\begin{array}{r}\text { Total identified } \\
\text { peaks } \%\end{array}$ \\
\hline 1 & $\alpha$-Terpinolene & 0.01 & 13 & Cycloheptasiloxane & 0.42 \\
2 & Bicyclohexane & 0.10 & 14 & Tricycloheptane & 0.04 \\
3 & Limonene oxide & 39.47 & 15 & $\alpha$-Pinene & 0.03 \\
4 & Isolimonene & 1.31 & 16 & Camphene & 0.06 \\
5 & 4,8-Epoxy-p-menth-1-ene & 0.27 & 17 & Sabinene & 0.09 \\
6 & Methyl chavicol & 2.05 & 18 & $\beta$-Pinene & 27.05 \\
7 & Linalool & 0.78 & 19 & $\beta$-Myrcene & 0.26 \\
8 & 2-Cyclohexen & 0.65 & 20 & $\gamma$-Terpinene & 0.61 \\
9 & $\alpha$-Fenchyl acetate & 0.35 & 21 & $\delta$ 3-Carene & 0.06 \\
10 & Naphthalene & 18.87 & 22 & Limonene & 0.06 \\
11 & Methyl eugenol & 3.22 & 23 & $c i s$-Ocimene & 0.15 \\
12 & Spathulenol & 4.05 & 24 & $\beta$-Ocimene & 0.04 \\
\hline
\end{tabular}

\subsection{Blood biochemistry}

Serum biochemical parameters were examined at 42 days of age. After $12 \mathrm{~h}$ without feeding, blood samples were collected in nonheparinized tube from eight birds in each treatment by puncturing the brachial vein and the blood was cen- trifuged at $2000 \times g$ for $15 \mathrm{~min}$ to obtain serum. Individual serum samples were analyzed for total cholesterol, HDL, LDL, and triglyceride using an automatic analyzer (Alcyon 300, Abbott Park, USA) and the kit package manufactured by Pars Azmoon Company, Tehran, Iran. 
Table 3. The effects of experimental diets on performance of broilers at different ages.

\begin{tabular}{|c|c|c|c|c|c|c|c|c|}
\hline \multirow{2}{*}{$\begin{array}{l}\text { Performance } \\
\text { parameters }\end{array}$} & \multicolumn{8}{|c|}{ Dietary treatments } \\
\hline & Control & Avilamycin & Protexin & $\begin{array}{r}\text { BEO } \\
\left(200 \mathrm{mg} \mathrm{kg}^{-1}\right)\end{array}$ & $\begin{array}{r}\text { BEO } \\
\left(400 \mathrm{mg} \mathrm{kg}^{-1}\right)\end{array}$ & $\begin{array}{r}\text { BEO } \\
\left(600 \mathrm{mg} \mathrm{kg}^{-1}\right)\end{array}$ & SEM & $P$ value \\
\hline \multicolumn{9}{|c|}{ Body weight gain $\left(\mathrm{g} \mathrm{d}^{-1} \mathrm{bird}^{-1}\right)$} \\
\hline 1-14 days & 22.47 & 23.69 & 21.61 & 22.50 & 22.61 & 23.56 & 0.56 & 0.1446 \\
\hline 15-28 days & 46.34 & 46.57 & 45.56 & 46.96 & 45.81 & 46.68 & 2.04 & 0.9961 \\
\hline 29-42 days & 64.54 & 62.81 & 61.96 & 68.33 & 69.09 & 65.77 & 4.25 & 0.7997 \\
\hline $1-42$ days & 44.45 & 44.36 & 43.04 & 45.93 & 45.84 & 45.34 & 1.18 & 0.5192 \\
\hline \multicolumn{9}{|c|}{ Daily feed intake $\left(\mathrm{g} \mathrm{d}^{-1} \mathrm{bird}^{-1}\right)$} \\
\hline 1-14 days & 33.49 & 32.76 & 30.35 & 32.20 & 32.83 & 41.49 & 3.67 & 0.3711 \\
\hline $15-28$ days & 71.56 & 74.39 & 67.58 & 69.01 & 73.01 & 62.99 & 4.18 & 0.4504 \\
\hline 29-42 days & 132.87 & 113.17 & 134.01 & 133.55 & 132.61 & 147.44 & 8.29 & 0.1749 \\
\hline $1-42$ days & 78.98 & 73.44 & 77.31 & 78.25 & 79.48 & 83.98 & 2.46 & 0.1384 \\
\hline \multicolumn{9}{|c|}{ Feed : gain $(g: g)$} \\
\hline 1-14 days & 1.45 & 1.38 & 1.40 & 1.43 & 1.45 & 1.76 & 0.15 & 05210 \\
\hline 15-28 days & 1.55 & 1.60 & 1.18 & 1.47 & 1.60 & 1.37 & 0.09 & 0.4764 \\
\hline 29-42 days & 2.06 & 1.82 & 2.19 & 2.00 & 1.99 & 2.24 & 0.19 & 0.6690 \\
\hline $1-42$ days & 1.78 & 1.66 & 1.80 & 1.71 & 1.74 & 1.85 & 0.07 & 0.5188 \\
\hline
\end{tabular}

* BEO: basil essential oil.

\subsection{Carcass characteristics}

Forty-eight broilers (four males and four females each group) were sampled randomly for carcass evaluations at 42 days of age, slaughtered and weighed. Their feathers were plucked and the carcasses gutted by hand. The whole carcass, breast, thigh, abdominal fat pad, empty gizzard, liver, and heart were excised and weighed individually. The carcass yields were calculated as a percentage of the preslaughter live body weights of broiler chickens. The weights of these internal organs were expressed as a percentage of live body weight.

Data from all response variables were subjected to oneway analysis of variance by applying the SAS program (SAS, 2005) using a general liner model (GLM). Significant differences among treatment means were separated using Tukey's test (Tukey, 1949) at $5 \%$ probability.

\section{Results}

\subsection{Broiler performance}

The results for body weight gain, feed intake and feed conversion ratio of the broilers are presented in Table 3. These results suggested that the supplementation of starter and grower diets with basil essential oil, protexin and avilamycin had no significant effect on feed intake. Additionally, body weight gain was similar among all treatments between different periods. There were no differences in feed conversion ratio between treatments.

\subsection{Blood biochemistry}

The effects of treatments on triglyceride, total cholesterol, and high- and low-density lipoproteins are illustrated in Table 4. Addition of basil essential oil to diet did not affect serum cholesterol or high- and low-density lipoproteins, but feeding $400 \mathrm{ppm}$ basil essential oil resulted in a marked increase in the concentration of the triglyceride $(P<0.05)$ in comparison to the control group.

\subsection{Carcass traits}

Results of experiment indicated that carcass yields and the fresh and relative weights (g) of the breast, thigh, gizzard, liver and heart of broilers at 42 days were not affected by dietary treatments (Table 5). In contrast, the abdominal fat decreased with incorporation of $200 \mathrm{ppm}$ basil essential oil $(P<0.05)$ when compared to antibiotic treatment.

\section{Discussion}

\subsection{Broiler performance}

Essential oil fed to broilers gave live performance levels similar to those of the antibiotic growth promoter and probiotic, results that agree with Gunal et al. (2006), Hosseini et al. (2013a) and Azadegan Mehr et al. (2014). Although it was expected that supplementing the dietary herbs would stimulate the growth performance of broilers, research on herbal plant extracts has yielded contradictory outcomes. In con- 
Table 4. The effects of experimental diets on serum lipid metabolites of broilers at 42 days of age.

\begin{tabular}{lrrrr}
\hline & \multicolumn{4}{c}{ Treatment } \\
\cline { 2 - 5 } Traits & $\begin{array}{r}\text { Cholesterol } \\
\left(\mathrm{mg} \mathrm{dl}^{-1}\right)\end{array}$ & $\begin{array}{r}\text { Triglyceride } \\
\left(\mathrm{mg} \mathrm{dl}^{-1}\right)\end{array}$ & $\begin{array}{r}\text { HDL } \\
\left(\mathrm{mg} \mathrm{dl}^{-1}\right)\end{array}$ & $\begin{array}{r}\text { LDL } \\
\left(\mathrm{mg} \mathrm{dl}^{-1}\right)\end{array}$ \\
\hline Control & 102 & $50.43^{\mathrm{b}}$ & 53.40 & 40.73 \\
Avilamycin & 108.29 & $73.43^{\mathrm{ab}}$ & 51.69 & 41.91 \\
Protexin & 109.25 & $58.25^{\mathrm{ab}}$ & 58.20 & 44.27 \\
BEO $\left(200 \mathrm{mg} \mathrm{kg}^{-1}\right)$ & 116.86 & $72.14^{\mathrm{ab}}$ & 46.80 & 51.10 \\
BEO $\left(400 \mathrm{mg} \mathrm{kg}^{-1}\right)$ & 116.63 & $78.25^{\mathrm{a}}$ & 50.17 & 50.80 \\
BEO (600 $\left.\mathrm{mg} \mathrm{kg}^{-1}\right)$ & 118.86 & $60.43^{\mathrm{ab}}$ & 52.71 & 54.06 \\
SEM & 7.19 & 5.40 & 3.47 & 5.85 \\
$P$ value & 0.5554 & 0.0055 & 0.3864 & 0.4954 \\
\hline
\end{tabular}

Means within a column with no common letters are significantly different $(P<0.05) .{ }^{*}$ BEO: basil essential oil.

Table 5. The effects of experimental diets on carcass traits of broilers at 42 days of age (as percentage of live body weight).

\begin{tabular}{lrrrrrrr}
\hline & \multicolumn{7}{c}{ Traits } \\
\cline { 2 - 8 } Treatment & $\begin{array}{r}\text { Carcass } \\
(\%)\end{array}$ & $\begin{array}{r}\text { Breast } \\
(\%)\end{array}$ & $\begin{array}{r}\text { Thigh } \\
(\%)\end{array}$ & $\begin{array}{r}\text { Abdominal } \\
\text { fat }(\%)\end{array}$ & $\begin{array}{r}\text { Liver } \\
(\%)\end{array}$ & $\begin{array}{r}\text { Gizzard } \\
(\%)\end{array}$ & $\begin{array}{r}\text { Heart } \\
(\%)\end{array}$ \\
\hline Control & 69.87 & 22.03 & 22.42 & $1.74^{\mathrm{ab}}$ & 2.64 & 2.81 & 0.58 \\
Avilamycin & 69.57 & 22.63 & 23.20 & $1.95^{\mathrm{a}}$ & 2.83 & 3.57 & 0.58 \\
Protexin & 71.93 & 22.53 & 23.66 & $1.46^{\mathrm{ab}}$ & 3.00 & 3.50 & 0.66 \\
BEO $\left(200 \mathrm{mg} \mathrm{kg}^{-1}\right)$ & 72.98 & 22.36 & 24.36 & $1.09^{\mathrm{b}}$ & 2.82 & 3.35 & 0.64 \\
BEO $\left(400 \mathrm{mg} \mathrm{kg}^{-1}\right)$ & 69.67 & 22.27 & 22.91 & $1.36^{\mathrm{ab}}$ & 2.89 & 2.65 & 0.62 \\
BEO $\left(600 \mathrm{mg} \mathrm{kg}^{-1}\right)$ & 71.45 & 22.41 & 22.56 & $1.47^{\mathrm{ab}}$ & 2.83 & 2.76 & 0.71 \\
SEM & 1.13 & 0.56 & 0.82 & 0.19 & 0.16 & 0.29 & 0.04 \\
$P$ value & 0.1882 & 0.1572 & 0.9042 & 0.0443 & 0.6244 & 0.0959 & 0.1433 \\
\hline
\end{tabular}

Means within a column with no common letters are significantly different $(P<0.05) .{ }^{*}$ BEO: basil essential oil.

trast to our result, Abbas (2010), Osman et al. (2010) and Onwurah et al. (2011) reported that addition of basil leaf and seed to the diet had a beneficial effect on feed intake, body weight gain and feed conversion ratio. In the present study, results agreed with the finding of Nweze and Ekwe (2012), who found no difference in the performance of broilers when basil extract was supplemented in diets.

Antibiotics, such as avilamycin, at growth-promoting levels have been shown to improve the growth and feed efficiency of chickens (Wellenreiter et al., 2000; Yakhkeshi et al., 2011). But our results are in agreement with those Ceylan and Ciftci (2003), Gunal et al. (2006) and Eseceli et al. (2010), who reported that the supplementation of a probiotic or an antibiotic growth promoter did not have any effect on weight gain and feed conversion ratio. The results showed that probiotics did not have any significant effect on performance in different periods. According to Nunes et al. (2012), probiotics do not always have positive outcomes in relation to weight gain and feed conversion of poultry; this is due to several variables, such as poultry health, duration of poultry house downtime and environmental contamination levels.
In general, the lack of significant influence of the additives on performance could be attributed to the composition of the basal diet and/or the environmental conditions. Our trial was performed under ideal conditions and the diet fed in different periods consisted of highly digestible ingredients, so bacterial growth in the intestine may have been limited. As a result of this, the growth promotion may have been affected.

\subsection{Blood biochemistry}

Serum biochemistry is a labile biochemical system which can reflect the condition of the body and the changes happening to it under the influence of internal and external factors. It is possible that both the short feeding period and the relatively low doses may have been implicated in the failure of basil essential oil to reduce plasma triglyceride and cholesterol level. Furthermore, it is well known that the absence or presence of cholesterolemic effects of dietary components in an animal depend on various factors such as breed, gender and age, and also on the composition of the feed (Toghyani et al., 2010). 
These findings concur with the data of Demir et al. (2005), who indicated that the supplementation of dietary thyme powder $\left(1 \mathrm{~g} \mathrm{~kg}^{-1}\right)$ for 42 days numerically increased plasma cholesterol and triglyceride levels compared to the control. Osman et al. (2010) reported that feeding dietary basil leaf powder for 42 days did not significantly influence the plasma cholesterol and triglyceride level in broilers. However, Abbas (2010) reported that feeding dietary basil seed $\left(3 \mathrm{~g} \mathrm{~kg}^{-1}\right)$ significantly reduced the plasma cholesterol level in broilers. The results obtained do not agree with those reported by Azadegan Mehr et al. (2014) and Hosseini et al. (2013b), who found that adding protexin to broilers' rations significantly decreased plasma total cholesterol. Eslami et al. (2010) and Hosseini et al. (2013a) added avilamycin to the diets of broilers and reported that no significant differences in plasma lowand high-density lipoprotein, total cholesterol or triglyceride were observed. Our results are in agreement with previous studies.

\subsection{Carcass traits}

Similar to our findings, Hernandez et al. (2004) found no differences in gizzard, liver and pancreas weights of broiler chickens fed with wheat-soybean-meal-based diets supplemented with plant extracts from the Labiatae family compared to the avilamycin group. Also, our findings on carcass traits are in agreement with those of Osman et al. (2010), who did not report any significant influence of dry basil leaf supplement on the relative weights of the gizzard, liver, heart and carcass at slaughter age in broilers. In another previous experiment, Abbas (2010) reported that organ weights and carcass characteristics were not affected by supplementing diet with $3 \mathrm{~g} \mathrm{~kg}^{-1}$ basil seed. This result is in agreement with the results of Ceylan and Ciftci (2003), Chowdhury et al. (2009) and Eseceli et al. (2010), who reported that there was no significant effect on carcass weight in broiler chicks fed a diet supplemented with avilamycin. Similarly, Saleh (2014) reported that supplementation with avilamycin did not significantly affect the liver weight of broilers.

Results showed that probiotic did not have any significant effect on carcass weight, abdominal fat and internal organs weight percentage (liver, heart and gizzard). Azadegan Mehr et al. (2014) found no significant differences in carcass traits among a medicinal plant group, a probiotic group, and a control group. Similar results were observed in the study of Nunes et al. (2012) with addition of probiotics to broiler diets. Antimicrobial properties of basil essential oil ingredients such as methyl chavicol and $\alpha$-pinene have been shown in various papers (Sokovic and van Griensven, 2006; Hanif et al., 2011). Given that most of the components of basil essential oil used in this study are comprised of methyl chavicol and $\alpha$-pinene, therefore, we can attribute the reduction in abdominal fat to the antibacterial effect of basil essential oil. Studies have shown that reducing the population of harmful bacteria prevents the breakdown of feed amino acids and proteins in the gut, and with better absorption, amino acids used in the synthesis of proteins, and with their accumulation in the breast and thigh, improve their weights (Lee et al., 2003a). In this study, $200 \mathrm{ppm}$ basil essential oil, in addition to reducing the relative weight of abdominal fat, increases the relative weights of thigh and breast.

\section{Conclusions}

The results of the present study showed that an antibiotic growth promoter (avilamycin), a probiotic (protexin) and essential oil (basil) treatments in broiler diets have no beneficial effects on the growth performance of broilers, probably due to low levels applied or the composition of basal diet and hygienic conditions of the experiment. Also, dietary supplementation with basil essential oil decreased abdominal fat and did not induce any adverse effects on chicks' lipid profiles. Therefore, future research efforts should continue to evaluate the effectiveness of the dietary herbal growth promoters and their specific effects on performance and blood parameters.

Author contributions. S. R. Riyazi carried out the experiment and prepared the manuscript. Y. Ebrahimnezhad helped to modify the manuscript. S. A. Hosseini designed and coordinated the experiment. A. Meimandipour measured the blood parameters. A. Ghorbani participated in the design of the study and performed the statistical analysis.

Acknowledgements. This article is part of a $\mathrm{PhD}$ thesis from the Department of Animal Science, Islamic Azad University, Shabestar Branch (thesis supervisors: Y. Ebrahimnezhad and S. A. Hossieni). The authors would like to thank all staff of the Animal Science Research Institute (ASRI) for providing necessary facilities for carrying out this research.

Edited by: S. Maak

Reviewed by: two anonymous referees

\section{References}

Abbas, R. J.: Effect of using fenugreek, parsley and sweet basil seeds as feed additives on the performance of broiler chickens, Int. J. Poult. Sci., 9, 278-282, 2010.

Alcicek, A., Bozkurt, M., and Çabuk, M.: The effects of an essential oil combination derived from selected herbs growing wild in Turkey on broiler performance, S. Afr. J. Anim. Sci., 33, 89-94, 2003.

Azadegan Mehr, M., Hassanabadi, A., Nassiri Moghaddam, H., and Kermanshahi, H.: Supplementation of clove essential oils and probiotic to the broiler's diet on performance, carcass traits and blood components, Iran. J. Appl. Anim. Sci., 4, 117-122, 2014. 
Bolukbasi, S. C., Erhan, M. K., and Kaynar, O.: The effect of feeding thyme, sage and rosemary oil on laying hen performance, cholesterol and some proteins ratio of egg yolk and Escherichia coli count in feces, Arch. Geflugelkd., 72, 231-237, 2008.

Botsoglou, N. A., Florou-Paneri, P., Christaki, E., Fletouris, D. J., and Spais, A. B.: Inhibition of lipid oxidation in long-term frozen stored chicken meat by dietary oregano essential oil and á-tocopheryl acetate supplementation, Food Res. Int., 36, 207213, 2003.

Botsoglou, N. A., Christaki, E., Florou-Paneri, P., Giannenas, I., Papageorgiou, G., Spais, A. B.: The effect of a mixture of herbal essential oils or $\alpha$ - tocopheryl acetate on performance parameters and oxidation of body lipid in broilers, S. Afr. J. Anim. Sci., 34, 52-61, 2004.

Bozkurt, M., Kucukyilmaz, K., Pamukcu, M., Cabuk, M., Alcicek, A., and Catli, A. U.: Long-term effects of dietary supplementation with an essential oil mixture on the growth and laying performance of two layer strains, Ital. J. Anim. Sci., 11, 23-28, 2012.

Brenes, A. and Roura, E.: Essential oils in poultry nutrition: main effects and modes of action, Anim. Feed. Sci. Technol., 158, 114, 2010.

Case, G. L., He, L., Mo, H., Elson, C. E.: Induction of geranyl pyrophosphate pyrophosphatase activity by cholesterol-suppressive isoprenoids, Lipids, 30, 357-359, 1995.

Ceylan, N. and Ciftci, I.: The effects of some alternative feed additives for antibiotic growth promoters on the performance and gut microflora of broiler chicks, Turk. J. Vet. Anim. Sci., 27, 727733, 2003

Chiang, S. H. and Hsieh, W. M.: Effect of Direct Fed Microorganism on Broiler growth performance and litter ammonia level, Asian. Australas. J. Anim. Sci., 8, 159-162, 1995.

Chowdhury, R., Islam, K. M. S., Khan, M. J., Karim, M. R., Haque, M. N., Khatun, M., and Pesti, G. M.: Effect of citric acid, avilamycin, and their combination on the performance, tibia ash, and immune status of broilers, Poult. Sci., 88, 1616-1622, 2009.

Demir, E., Sarica, S., Ozcan, M. A., and Suicmez, M.: The use of natural feed additives as alternative to an antibiotic growth promoter in broiler diets, Arch. Geflugelkd., 69, 110-116, 2005.

Dhama, K., Latheef, S. K., Mani, S., Samad, H. A., Karthik, K., Tiwari, R., Khan, R. U., Alagawany, M., Farag, M. R., Alam, G. M., Laudadio, V., and Tufarelli, V.: Multiple beneficial applications and modes of action of herbs in poultry health and production A review, Int. J. Pharmacol., 11, 152-176, 2015.

Eseceli, H., Demir, E., Degirmencioglu, N., and Bilgic, M.: The effects of Bio-Mos mannan oligosaccharide and antibiotic growth promoter performance of broilers, J. Anim. Vet. Adv., 9, 392395,2010

Eslami, M., Baghaei, M., Mamouei, M., Chaji, M., and Ashayerizadeh, A.: Effects of avilamycin, formycingold and FYTO-MIX on serum lipid concentrations of young broilers, J. Anim. Vet. Adv., 9, 108-111, 2010.

Fuller, R.: Probiotics in man and animals, J. Appl. Bacteriol., 66, 365-378, 1989.

Gunal, M., Yayli, G., Kaya, O., Karahan, N., and Sulak, O.: The effects of antibiotic growth promoter, probiotic or organic acid supplementation on performance, intestinal microflora and tissue of broilers, Int. J. Poult. Sci., 5, 149-155, 2006.

Hanif, M. A., Al-Maskari, Y. M., Al-Maskari, A., Al-Shukaili, A., Al-Maskari, A. Y., and Al-Sabahi, J. N.: Essential oil com- position, antimicrobial and antioxidant activities of unexplored Omani basil, J. Med. Plant. Res., 5, 751-757, 2011.

Hernandez, F., Madrid, J., Garcia, V., Orengo, J., and Megias, M. D.: Influence of two plant extracts on broilers performance, digestibility, and digestive organ size, Poult. Sci., 83, 169-174, 2004.

Hosseini, S. A., Naseri, M., Zarai, A., Lotfollahian, H., Riyazi, S. R., and Meimandipour, A.: Effect of lemon oil on gastrointestinal tract, blood parameter and immune responses in broilers, Ann. Biol. Res., 4, 47-51, 2013a.

Hosseini, S. A., Meimandipour, A., Alami, F., Mahdavi, A., MohitiAsli, M., Lotfollahian, H., and Cross, D.: Effects of ground thyme and probiotic supplements in diets on broiler performance, blood biochemistry and immunological response to sheep red blood cells, Ital. J. Anim. Sci., 12, 116-120, 2013 b.

Khan, R. U., Naz, S., Nikousefat, Z., Tufarelli, V., and Laudadio, V.: Thymus vulgaris: alternative to antibiotics in poultry feed, World Poult. Sci. J., 68, 401-408, 2012.

Lavinia, S., Gabi, D., Drinceanu, D., Steff, D., Daniela, M., Julean, C., Ramona, T., and Corcionivoschi, N.: The effect of medicinal plants and plant extracted oils on broiler duodenum morphology and immunological profile, Rom. Biotech. Lett., 14, 4606-4614, 2009.

Lee, K. W., Everts, H., Kappert, H. J., Frehner, M., Losa, R., and Beynen, A. C.: Effects of dietary essential oil components on growth performance, digestive enzymes and lipid metabolism in female broiler chickens, Br. Poult. Sci., 44, 450-457, 2003 a.

Lee, K. W., Everts, H., Kappert, H. J., Yeom, K. H., and Beynen, A. C.: Dietary carvacrol lowers body weight gain but improves feed conversion in female broiler chickens, J. Appl. Poultry Res., 12, 394-399, 2003b.

Nunes, R. V., Scherer, C., Pozza, P. C., Eyng, C., Bruno, L. D. G., and Vieites, F. M.: Use of probiotics to replace antibiotics for broilers, Rev. Bras. Zootecn., 41, 2219-2224, 2012.

Nweze, B. O. and Ekwe, O. O.: Growth performance, gut and haemo-microbial study of finishing broilers fed african sweet basil (Ocimum Gratissimum) leaf extract, Ozean. J. Appl. Sci., 5, 185-191, 2012.

Onwurah, F. B., Ojewola, G. S., and Akomas, S.: Effect of basil (Ocimum Basilicum L.) on coccidial infection in broiler chicks, Acad. Res. Int., 1, 438-442, 2011.

Osman, M., Yakout, H. M., Motawe, H. F., and Ezz El-Arab, W. F.: Productive, physiological, immunological and economical effects of supplementing natural feed additives to broiler diets, Egypt. Poult. Sci., 30, 25-53, 2010.

Qureshi, A. A., Din, Z. Z., Abuirmeileh, N., Burger, W. C., Ahmad, Y., and Elson, C. E.: Suppression of avian hepatic lipid metabolism by solvent extracts of garlic: impact on serum lipids, J. Nutr., 113, 1746-1755, 1983.

Sajjadi, S. E.: Analysis of the essential oils of two cultivated basil (Ocimum basilicum L.) from Iran, Daru, 14, 128-130, 2006.

Saleh, A. A.: Nigella seed oil as alternative to avilamycin antibiotic in broiler chicken diets, S. Afr. J. Anim. Sci., 44, 254-261, 2014

SAS Institute, SAS Users guide: Statistics, Version 9.12. SAS Institute Inc., Cary, NC, USA, 2005.

Sokovic, M. and van Griensven, L. J. L. D.: Antimicrobial activity of essential oils and their components against the three major pathogens of the cultivated button mushroom, Agaricus bisporus, Eur. J. Plant Pathol., 116, 211-224, 2006. 
Toghyani, M., Toghyani, M., Gheisari, A., Ghalamkari, G., and Mohammadrezaei, M.: Growth performance, serum biochemistry and blood hematology of broiler chicks fed different levels of black seed (Nigella sativa) and peppermint (Mentha piperita), Livest. Sci., 129, 173-178, 2010.

Traesel, C. K., Wolkmer, P., Schmidt, C., Silva, C. B., Paim, F. C., Rosa, A. P., Alves, S. H., Santurio, J. M., and Lopes, S. T. A.: Serum biochemical profile and performance of broiler chickens fed diets containing essential oils and pepper, Comp. Clin. Path., 20, 453-460, 2011.

Tukey, J. W.: Comparing individual means in the analysis of variance, Biometrics, 5, 99-114, 1949.

Vahdatpour, T., Nikpiran, H., Babazadeh, D., Vahdatpour, S., and Jafargholipour, M. A.: Effects of Protexin ${ }^{\circledR}$, Fermacto ${ }^{\circledR}$ and combination of them on blood enzymes and performance of Japanese quails (Coturnix Japonica), Ann. Biol. Res., 2, 283$291,2011$.
Wellenreiter, R. H., Mowrey, D. H., Stobbs, L. A., and d'Assonville, J. A.: Effects of avilamycin on performance of broiler chickens, Vet. Ther., 1, 118-124, 2000.

Yakhkeshi, S., Rahimi, S., and Gharib Naseri, K.: The effects of comparison of herbal extracts, antibiotic, probiotic and organic acid on serum lipids, immune response, GIT microbial population, intestinal morphology and performance of broilers, J. Med. Plants., 10, 80-95, 2011. 